
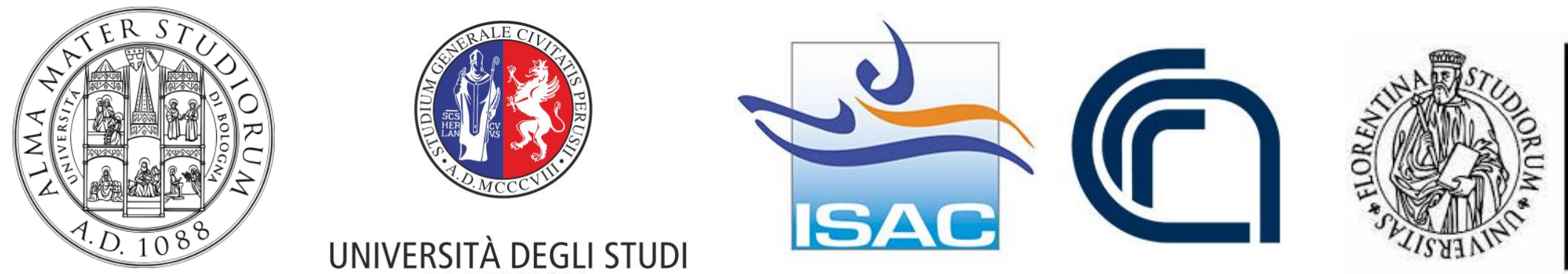

\title{
Analysis of multi-year near-surface ozone observations at the \\ WMO/GAW "Concordia" station, Antarctica
}

Davide Putero ${ }^{1}$, Rita Traversi ${ }^{2}$, Angelo Lupi ${ }^{3}$, Francescopiero Calzolari ${ }^{1}$, Maurizio Busetto ${ }^{1}$, Laura Tositti ${ }^{4}$, Stefano Crocchianti $^{5}$, Paolo Cristofanelli ${ }^{1}$

${ }^{1}$ CNR-ISAC, Bologna, Italy (d.putero@isac.cnr.it)

${ }^{2}$ University of Florence, Florence, Italy

${ }^{3}$ CNR-ISP, Bologna, Italy

${ }^{4}$ University of Bologna, Bologna, Italy

5 University of Perugia, Perugia, Italy 


\section{Outline}

- Near-surface ozone $\left(\mathrm{O}_{3}\right)$ variability at Dome $\mathrm{C}$

- Ozone Enhancement Events (OEEs)

- Possible influence of TCO

- Role of synoptic-scale air mass transport

- Role of deep stratospheric transport

- Upcoming work: the STEAR project

\begin{tabular}{lc|}
\hline & Contents lists available at ScienceDirect \\
ELSEVIER & Atmospheric Environment \\
\hline
\end{tabular}

Analysis of multi-year near-surface ozone observations at the WMO/GAW “Concordia" station $\left(75^{\circ} 06^{\prime} \mathrm{S}, 123^{\circ} 20^{\prime} \mathrm{E}, 3280 \mathrm{~m}\right.$ a.s.l. - Antarctica) 


\section{Ozone variability at Dome C}

- WMO/GAW "Concordia" station (Dome C) in the Eastern Antarctic plateau (3280 m a.s.I.)

- Location not strongly affected by katabatic winds, prevalent SW wind direction

- Near-surface $\mathrm{O}_{3}$ measurements performed with different UV absorption analyzers (Thermo Tei 49C, Thermo Tei 49i, and Dasibi 1108)
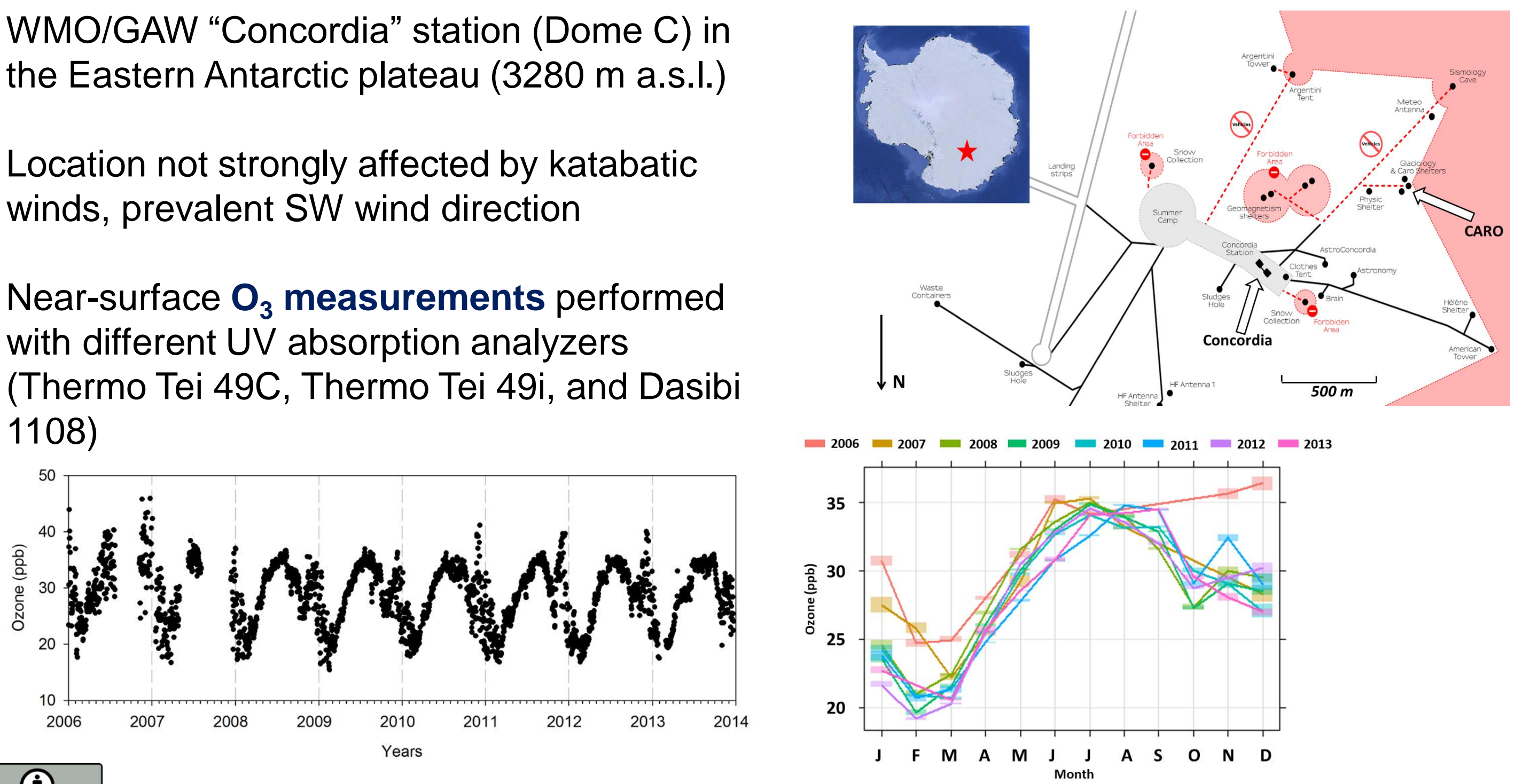


\section{Ozone Enhancement Events (OEEs)}

OEEs selection based on the following procedure:

- Calculate the «undisturbed» $\mathrm{O}_{3}$ annual cycle (sinusoidal fit)

- Calculate the PDF of the deviations of daily data from the sinusoidal fit, plus the application of a Gaussian fit to the PDF

- Compute a Gaussian fit for the PDF points beyond $1 \sigma$ of the Gaussian PDF, and the intersection between the two curves is the selected threshold value for identifying OEEs (i.e., 6 ppb)
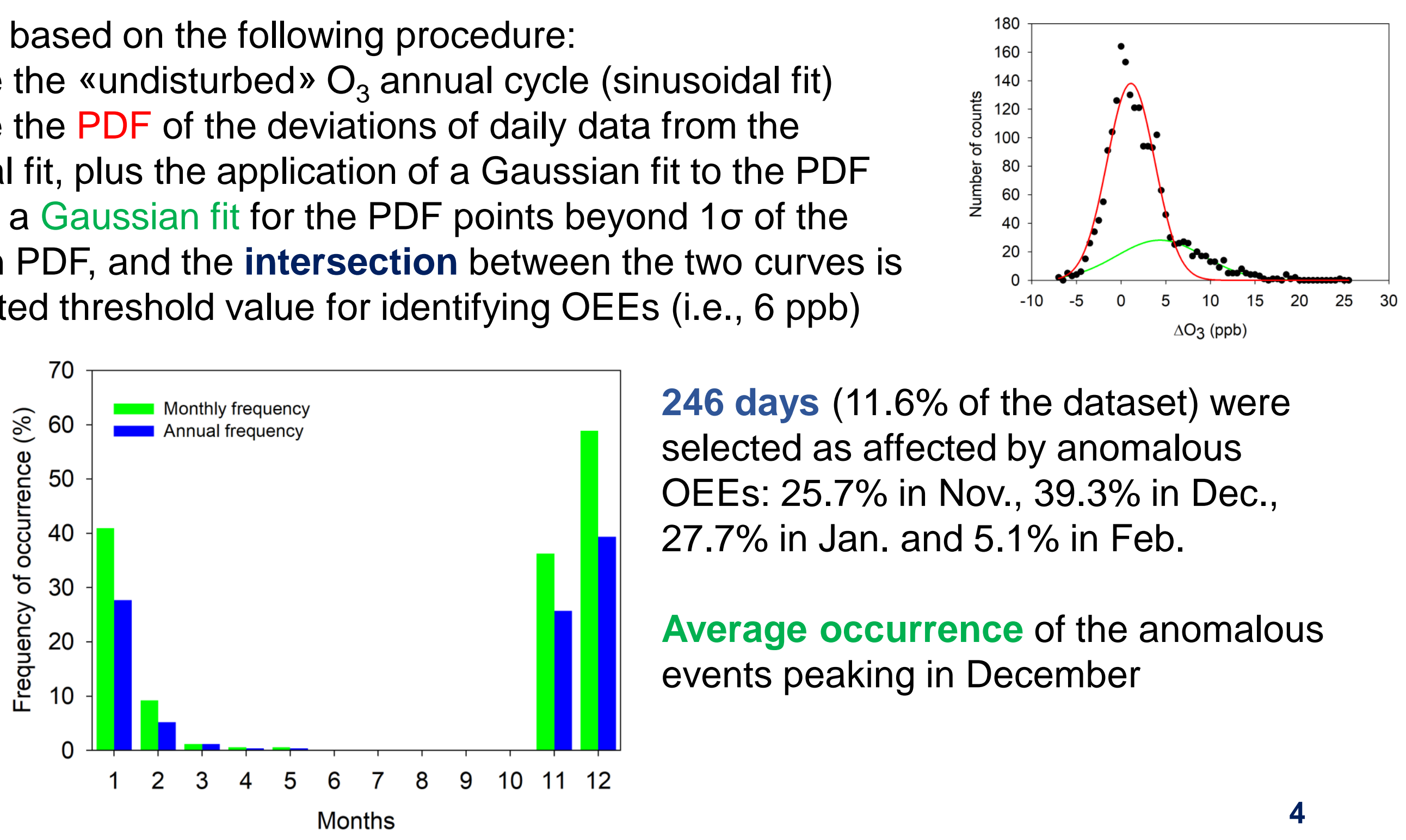

246 days ( $11.6 \%$ of the dataset) were selected as affected by anomalous OEEs: $25.7 \%$ in Nov., 39.3\% in Dec., $27.7 \%$ in Jan. and $5.1 \%$ in Feb.

Average occurrence of the anomalous events peaking in December 


\section{Possible influence of total column of ozone}

- No clear anti-correlation between $\mathrm{TCO}$ and $\mathrm{O}_{3}$ values during OEEs

- Positive significant correlation between OEEs and TCO observed in November

- This supports the finding by Frey et al. (2009) that the flux of $\mathrm{NO}_{X}$ in the surface atmospheric layer (and thus $\mathrm{O}_{3}$ production) only depends on second order from TCO variability
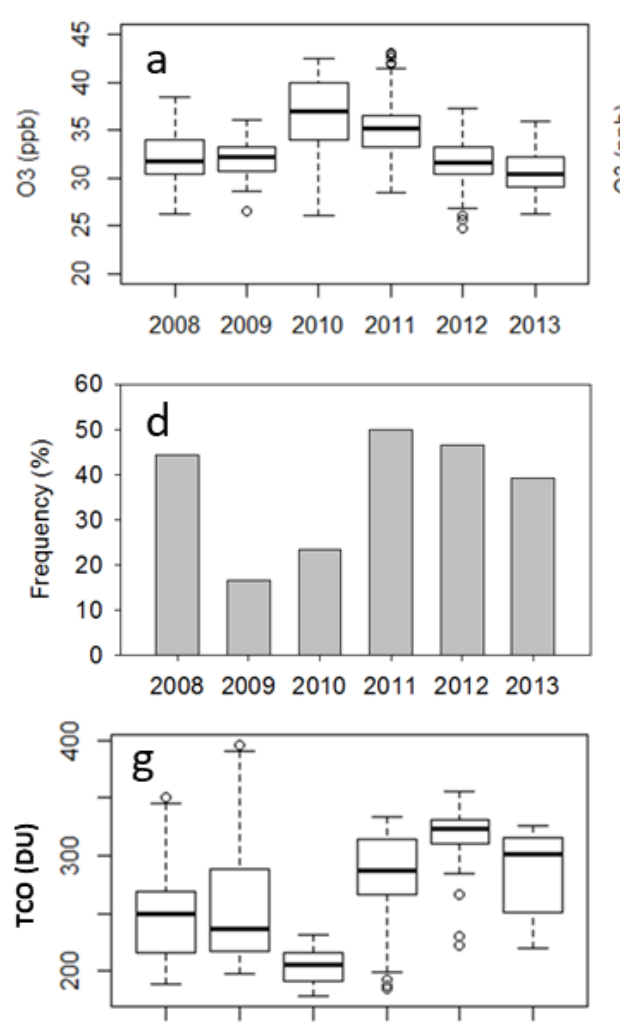

200820092010201120122013

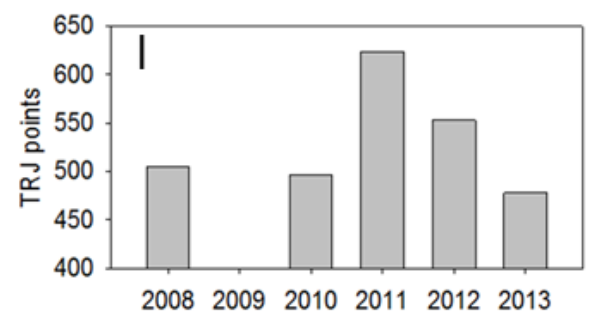

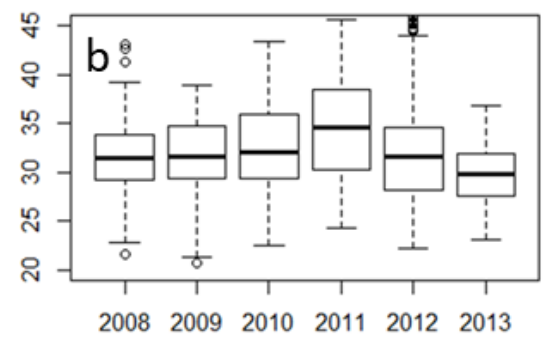
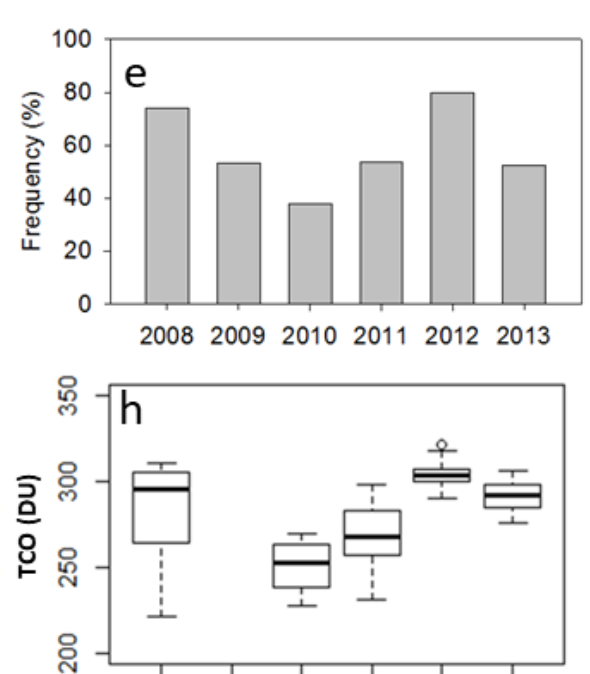

200820092010201120122013

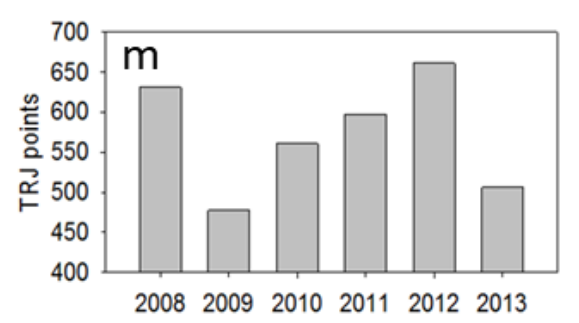

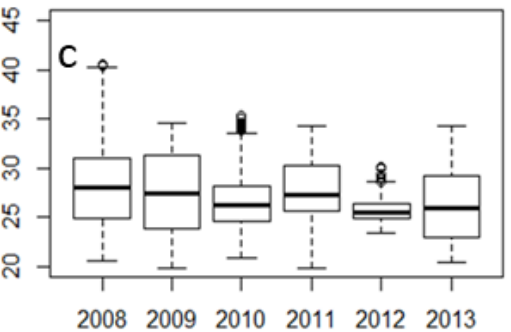
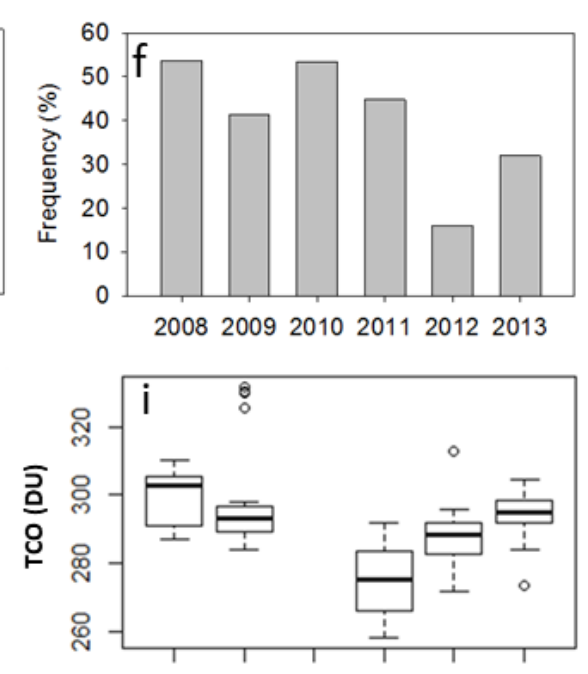

200820092010201120122013

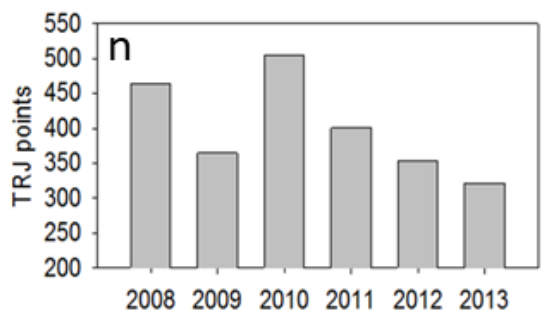




\section{Role of synoptic-scale air mass transport}

- 5-days LAGRANTO back-trajectories at Dome C

- Application of the potential source contribution function (PSCF)

- Connection between OEEs and the air masses which traveled over the East Antarctic plateau

- The permanence of air masses over the continental plateau is an important driver for the occurrence of OEEs at DMC, through accumulation processes
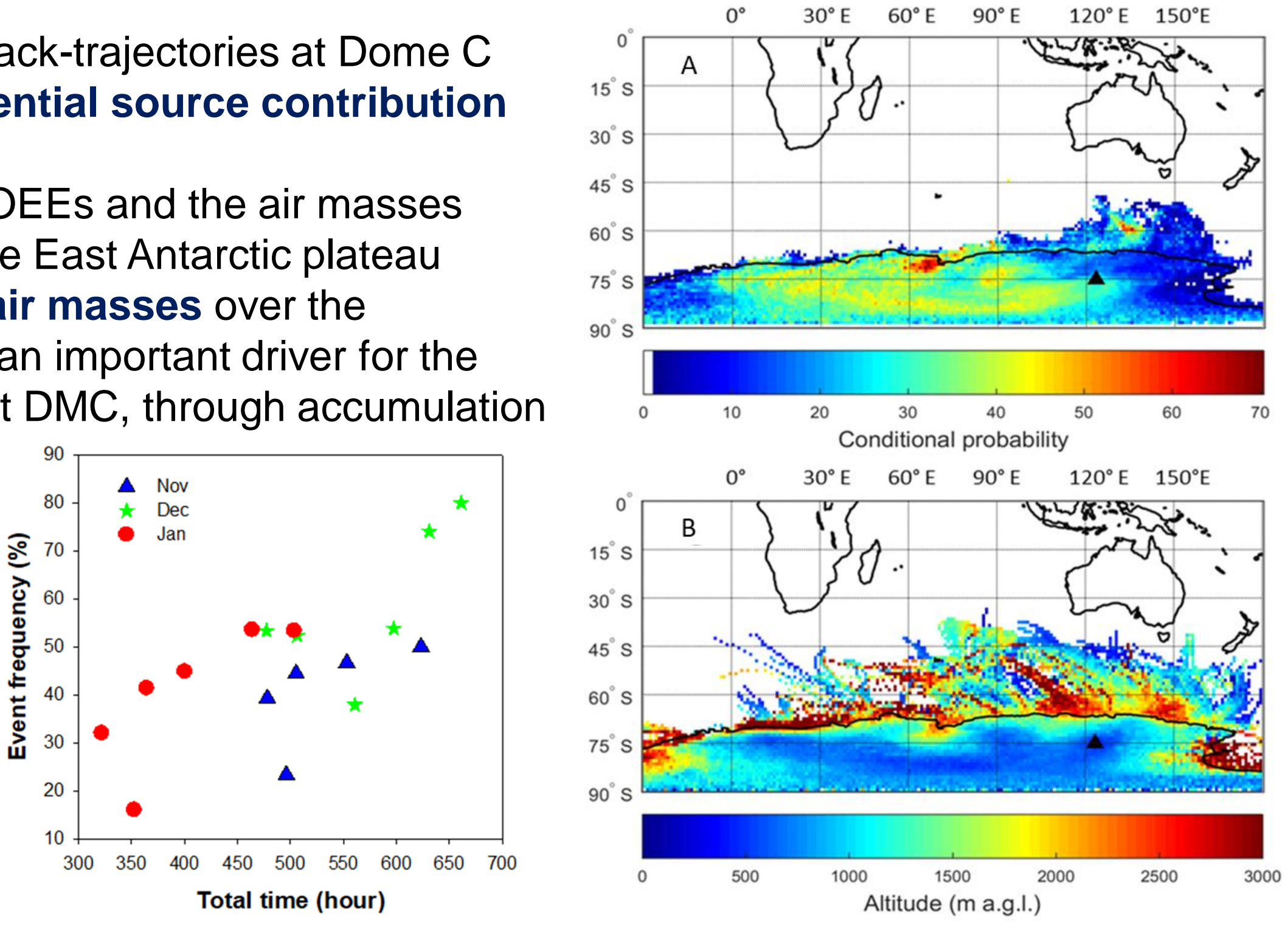


\section{Role of «deep» stratospheric transport}

- Application of the STEFLUX tool (Putero et al., 2016) over a target region around Dome C for investigating deep stratosphere-to-troposphere transport (STT) events

- Despite no clear seasonal cycle is visible, the occurrence of STT events is lower than $2 \%$ on a monthly basis

- STT can represent a source of nitrates for the Antarctic atmosphere through different processes

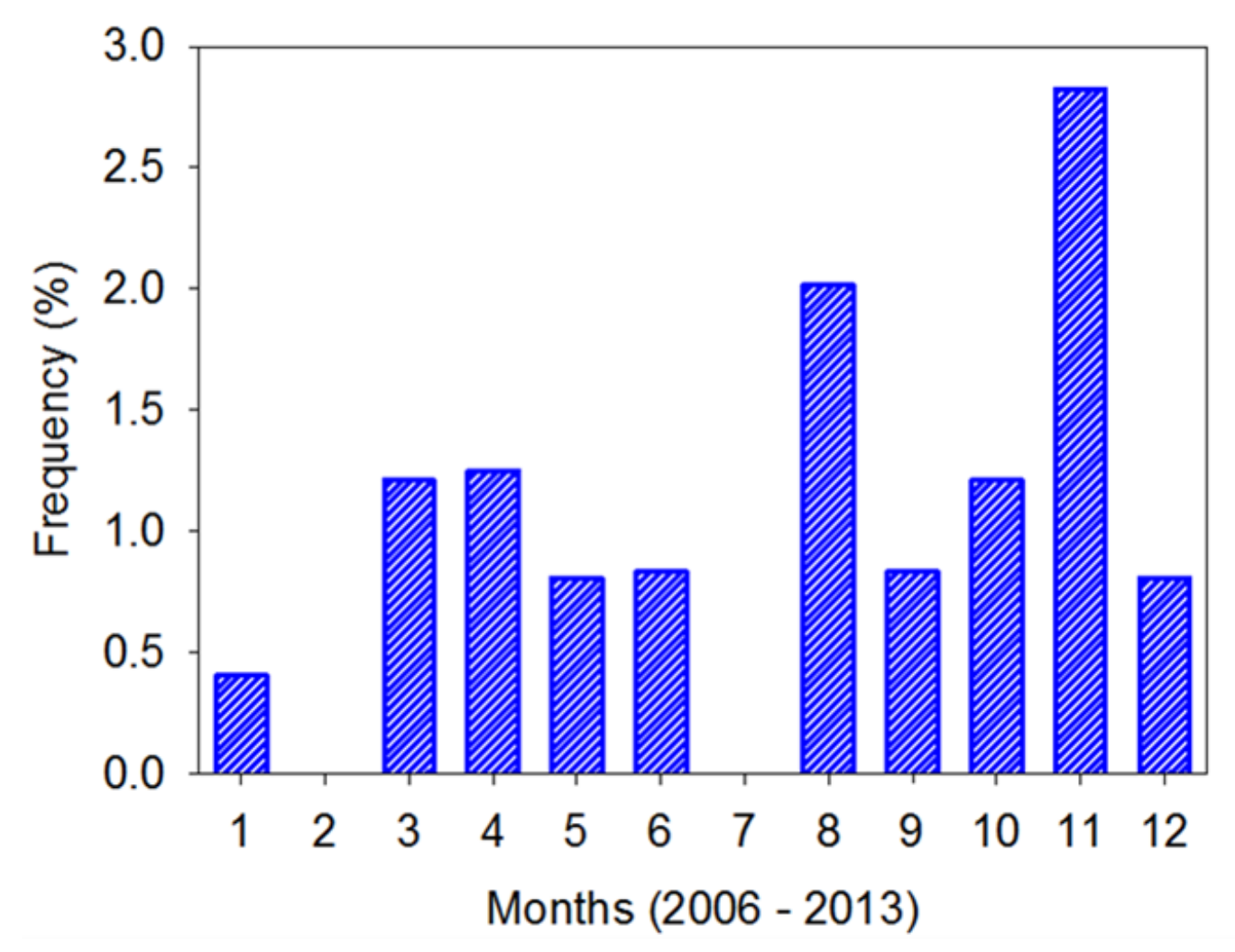

STT can be an input of nitrates, which can be recycled by the snowpack and released as $\mathrm{NO}_{x}$ under sunlight conditions, thus possibly favoring OEEs 


\section{Upcoming work: the STEAR project}

\section{STEAR - Stratosphere-to-Troposphere Exchange in the Antarctic Region}

2020-2022, funded by the Italian Antarctic Research Program (PNRA)

- Provide an assessment of stratosphere-to-troposphere exchange (STE) events in Antarctica, by using both observations and modeling outputs

- Continuous measurements of ${ }^{7} \mathbf{B e}$ at Dome $\mathbf{C}$, for the whole project duration

- Investigation of the STE impact on near-surface ozone, total ozone, aerosol chemistry, and nitrate in surface snow

- Analysis of simultaneous atmospheric composition datasets from Antarctic coastal observatories (i.e., Mario Zucchelli and Jang Bogo stations)

- Modeling analyses performed on different time scales, by using Lagrangian models (i.e., FLEXPART, HYSPLIT, and STEFLUX) 